\title{
Evaluation Method of the Vertical Well Hydraulic Fracturing Effect Based on Production Data
}

\author{
Debin Xia $\mathbb{D}^{1,2,3}$ Zhengming Yang, ${ }^{1,2,3}$ Daolun $\mathrm{Li}^{4}{ }^{4}$ Yapu Zhang, ${ }^{2,3}$ Ying $\mathrm{He}^{2,3}$ \\ Yutian Luo, ${ }^{1,2,3}$ Anshun Zhang, ${ }^{5}$ Wenming Wang, ${ }^{6}$ and Xinli Zhao ${ }^{10,2,3}$ \\ ${ }^{1}$ University of Chinese Academy of Sciences, Beijing 100049, China \\ ${ }^{2}$ Institute of Porous Flow and Fluid Mechanics, Chinese Academy of Sciences, Langfang, Hebei 065007, China \\ ${ }^{3}$ Department of Porous Flow \& Fluid Mechanics, Research Institute of Petroleum Exploration \& Development, \\ PetroChina Company Limited, Langfang, Hebei 065007, China \\ ${ }^{4}$ Hefei University of Technology, Hefei, Anhui 230009, China \\ ${ }^{5}$ CNOOC Research Institute Co., Ltd., Beijing 100028, China \\ ${ }^{6}$ Daqing Yushulin Oilfield Development Co., Ltd., PetroChina., Daqing, Heilongjiang 163453, China
}

Correspondence should be addressed to Xinli Zhao; ucaszxl@163.com

Received 26 March 2021; Accepted 18 September 2021; Published 2 November 2021

Academic Editor: Basim Abu-Jdayil Moh'd Ismail

Copyright (c) 2021 Debin Xia et al. This is an open access article distributed under the Creative Commons Attribution License, which permits unrestricted use, distribution, and reproduction in any medium, provided the original work is properly cited.

\begin{abstract}
Hydraulic fracturing technology has become a key technology for the development of low-permeability/tight oil and gas reservoirs. The evaluation on the postfracturing effect is imperative to the formulation and implementation of the fracturing and development plan. Based on the characteristics of the flow in fracture network after a large-scale hydraulic fracturing, a numerical method for evaluating the effect of fracturing in vertical well was established. This study conducts postfracturing effect evaluations to block C Oilfield's wells that underwent conventional fracturing and volumetric fracturing, respectively, proposes the definition of fracture network conductivity and its relationship with cumulative production, and analyzes the fracturing construction parameters. The results suggest that the conventional fracturing can only form a single fracture instead of a stimulated reservoir volume (SRV) region. However, the volumetric fracturing transformation can form a complex fracture network system and SRV region and meanwhile bring obvious increase in the production. The effective time lasts for a longer period, and the increase of average daily oil is 2.2 times more than that of conventional fracturing. Additionally, with the progress of the production, the SRV area within the core region of the volume transformation gradually decreased from $6664.84 \mathrm{~m}^{2}$ to $4414.45 \mathrm{~m}^{2}$; the SRV area of the outer region decreased from $7913.5 \mathrm{~m}^{2}$ to $5391.3 \mathrm{~m}^{2}$. As the progress develops, the equivalent permeability and the area of the fracture gradually decrease as the fracturing effect gradually weakens, and so does the conductivity of the network decreasing exponentially; a good correlation is observed between the conductivity of the fracture network, the cumulative production, and fracturing construction parameters, which can serve as the evaluation parameters for the fracturing effects and the basis for fracturing productivity prediction and provide a guidance for fracturing optimization design.
\end{abstract}

\section{Introduction}

As the technology of unconventional resource exploration and development advances, tight reservoirs and their production contribution have increased year by year and become a substantial part in China's current and future crude oil reserves [1-3]. The development of tight reservoirs has become the key role in the progress of enhancing national energy source security and realizing energy selfsufficiency. The tight oil and gas reservoirs are characterized by low permeability, poor pore throat structure, and no natural production [4-6]. The conventional development method can barely achieve profitability and thus requires volume fracturing which refers to the generation of fracture network by artificial approaches, improving the reservoir seepage capacity and the contact area between the fracture 
and the reservoir [7-11]. The evaluation of production after volume fracturing has always been the focus for petroleum engineers.

Methods evaluating fracturing effects can be distinguished into direct methods and indirect methods. The former one mainly includes microseismic, inclinometer, well temperature logging, and tracer distributed fiber. However, this method is limited by the monitoring method and time conditions and therefore can only detect the fracture effect at a certain point in time and cannot perform long-term monitoring [12]. At the same time, the indirect method does not restrict to the monitoring method and the required data is easy to obtain. Therefore, compared to the direct method, indirect approach is more widely used in the petroleum industry. Perrine proposed a pressure method for multiphase flow test [13]. He pointed out that if the flow coefficient and compression coefficient of a single-phase fluid are replaced by the total fluidity of the multiphase fluid and the comprehensive compression coefficient, the well test formula derived in the case of single-phase flow can also be used for a multiphase flow test well. Martin pointed out that through theoretical analysis, the essence of Perrine's pressure method is to ignore the saturation gradient in the reservoir [14]. Based on the method's well test analysis, the integrated flow coefficient, skin factor, and average formation pressure can be obtained. The production index of the well can also be obtained by analogy with the steady flow of the single-phase flow. Serra et al. proposed a method for calculating a relative permeability curve using unstable pressure drop or pressure recovery data [15]. Li et al. proposed a new production data analysis method to address the abrupt change issue based on the virtual equivalent time. The mathematical model with a variable flowrate provides new definitions of normalized pseudopressure and pseudotime with consideration of the pressure-dependent permeability for multifractured horizontal wells in shale gas reservoirs [16]. Hatzignatiou et al. studied the effect of wellbore storage on multiphase flow system pressure [17]. Zhang and Yang adopted a semianalytical technique to examine stresssensitive effect on the transient pressure responses of a multiple-fractured horizontal well in an unconventional reservoir with an arbitrary shape; sensitivity analysis on pressure responses and their corresponding derivative curves has been performed with respect to the convergence skin effect, boundary shape, maximum distance, and minimum fracture conductivity [18]. Xu et al. adopted a semianalytical pseudo-3-D geomechanical model to describe induced fracture network. The hydraulically stimulated volume is represented by a horizontally expanding ellipse containing a simplified fracture network consisting of two sets of vertical planar fractures perpendicular to one another. This model provides a mathematically equivalent description of the process of hydraulic fracture propagation and the characteristics of the induced fractures [19].

Lei established the concept of numerical well test model for the first time, considering the wellbore storage effect and skin effect [20]. Puchyr first proposed the concept of numerical well test model, which assumes that the fluid is an incompressible single-phase fluid under single well condi- tions and forms a corresponding reservoir numerical simulator [21]. Archer through the study of numerical well test models found that Green's function is the best choice for numerical interpretation models [22].

Meyer and Bazan aimed at the formation of complex fracture network structures with high conductivity after volume fracturing in oil wells based on the material balance and momentum conservation equations; the discrete fracture network is proposed. However, when using this model to calculate the fracture network parameters, it is necessary to combine the fracturing construction parameters and the in situ stress parameters, and the seepage field law of the well production stage after fracturing cannot be obtained [23]. $\mathrm{Xu}$ et al. implement a discrete fracture model (DFM) and use flexible Delaunay triangulation to represent individual fractures. Numerical simulations are conducted to investigate the influence of rock deformation on a reservoir with complex fracture network [24].

However, for tight reservoirs, it is difficult to derive analytical solutions for seepage equations under complex boundary conditions and for numerical well testing, previous works used simple grids that show certain limitation regardless of whether being structural or unstructured.

In this paper, based on the mathematical model of numerical well testing, we used the hybrid meshing method with radial mesh and constrained PEBI mesh to evaluate the fracturing effect based on the production data. This method was applied to the vertical wells undergoing either conventional fracturing or volumetric fracturing in a block of the C Oilfield, China, and evaluated and compared their effects after fracturing.

\section{Model Description}

2.1. Physical Model. Volumetric fracturing not only forms the main fractures but also creates a reformed zone composed of secondary fractures. After the fracturing transformation, the fracturing area becomes complicated and needs to be simplified in a numerical solution. Based on the black oil model, the following basic assumptions are proposed:

(1) the fluid flow in the reservoir satisfies the Darcy flow; (2) there are only oil and water phases in the model. The oil and water components are nonmiscible to each other, and there is no mass exchange between the two components; (3) the fluid in the reservoir is in a constant temperature and thermodynamic equilibrium; (4) considering the pressure sensitivity, both the fluid and the rock are compressible; (5) reservoir has heterogeneity and anisotropy; and (6) capillary force is negligible. The reservoir modification volume (SRV) formed by volumetric fracturing transformation is represented by "main fracture zone + secondary fracture zone." In this paper, the main fractures are viewed as a grid with infinite conductivity; the transformation is distinguished into the core area (main fracture affected area) and the outer area (secondary fracture affected area), and the equivalent permeability of the corresponding area is increased (Figure 1). The porosity and permeability of the core zone are relatively greater, while those 


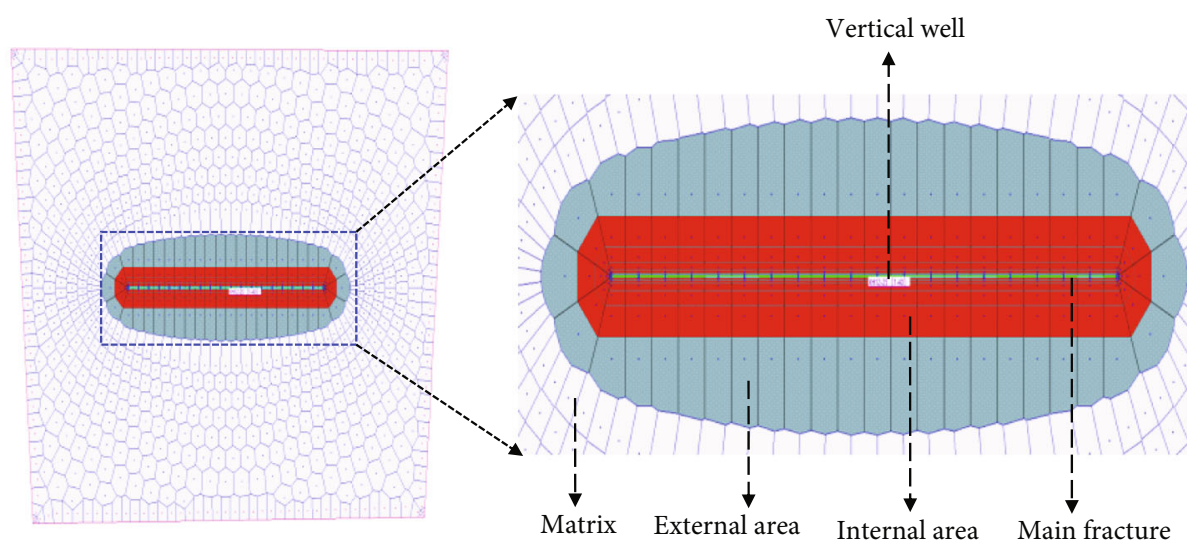

FIGURE 1: Schematic diagram of fracture meshing in the stimulated reservoir.

of the outer zone are less. The porosity and permeability of the unmodified zone are the basic parameters of the reservoir.

2.2. Mathematical Model. Based on the above assumption, the substitution of Darcy's law into the continuity equation can be derived from the following governing equation.

The oil phase equation is

$$
\nabla \cdot\left[\frac{K K_{\mathrm{ro}}}{\mu_{\mathrm{o}} B_{o}}\left(\nabla p_{\mathrm{o}}-\rho_{\mathrm{o}} g \nabla Z\right)\right]=\frac{\partial}{\partial t}\left(\frac{\phi S_{\mathrm{o}}}{B_{\mathrm{o}}}\right)+q_{\mathrm{o}}
$$

The water phase equation is

$$
\nabla \cdot\left[\frac{K K_{\mathrm{rw}}}{\mu_{\mathrm{w}} B_{\mathrm{w}}}\left(\nabla p_{\mathrm{w}}-\rho_{\mathrm{w}} g \nabla Z\right)\right]=\frac{\partial}{\partial t}\left(\frac{\phi S_{\mathrm{w}}}{B_{\mathrm{w}}}\right)+q_{\mathrm{w}}
$$

where $K$ is the mesh permeability, $\mu \mathrm{m}^{2} ; K_{\mathrm{ro}}$ and $K_{\mathrm{rw}}$ are the relative permeability of oil and water, dimensionless; $\mu$ is viscosity, Pa.s; $B$ is the formation volume coefficient; $p$ is pressure, $\mathrm{Pa} ; \rho$ is density, $\mathrm{kg} / \mathrm{m}^{3} ; g$ is gravitational acceleration, $\mathrm{m} / \mathrm{s}^{2} ; Z$ is vertical coordinate; $\phi$ is reservoir porosity; $S_{0}$ and $S_{\mathrm{w}}$ are oil and water saturation, dimensionless; $q_{\mathrm{o}}$ and $q_{\mathrm{w}}$ are the flowrate of oil and water for ground conditions, respectively, $\mathrm{m}^{3} /$ day; subscripts $\mathrm{o}$ and $\mathrm{w}$ represent oil phase and water phase, respectively.

The above two equations have four variables: $S_{\mathrm{o}}, S_{\mathrm{w}}, p_{\mathrm{o}}$, and $p_{\mathrm{w}}$. To solve the equation, two additional equations need to be added. Assume only oil and water exist in the reservoir.

$$
\begin{gathered}
S_{\mathrm{o}}+S_{\mathrm{w}}=1, \\
p_{\mathrm{o}}-p_{\mathrm{w}}=p_{\mathrm{c}},
\end{gathered}
$$

where $p_{c}$ is the capillary force of the oil phase and the water phase and a function of the water saturation and can be obtained from the oil-water phase flow experiment. The two variables in the governing equation can be eliminated by equations (3) and (4), and only two variables $q_{\mathrm{o}}$ and $S_{\mathrm{w}}$ are left to be solved.
Oil production equation

$$
q_{\mathrm{o}}=\frac{2 \pi K K_{\mathrm{ro}} h}{\mu_{\mathrm{o}} B_{\mathrm{o}} \ln \left(r_{\mathrm{e}} / r_{\mathrm{w}}\right)+S}\left(p_{i}-p_{\mathrm{wf}}\right) .
$$

Water production equation

$$
q_{\mathrm{w}}=\frac{2 \pi K K_{\mathrm{rw}} h}{\mu_{\mathrm{w}} B_{\mathrm{w}} \ln \left(r_{\mathrm{e}} / r_{\mathrm{w}}\right)+S}\left(p_{i}-p_{\mathrm{wf}}\right),
$$

where $r_{\mathrm{e}}$ is the distance from the grid adjacent to the fractures, $\mathrm{m} ; r_{\mathrm{w}}$ is the fracture width, $\mathrm{m}$; $h$ is the thickness of the grid, $\mathrm{m} ; S$ is the wellbore pollution coefficient, dimensionless; $p_{\mathrm{wf}}$ is the wellbore pressure, $\mathrm{Pa}$; and $p_{i}$ is the pressure of the grid adjacent to fracture, $\mathrm{Pa}$.

It is obvious from equations (5) and (6) that there is a certain relationship between oil production and water production:

$$
\frac{q_{\mathrm{o}}}{q_{\mathrm{w}}}=\frac{k_{\mathrm{ro}} / \mu_{\mathrm{o}} B_{\mathrm{o}}}{k_{\mathrm{rw}} / \mu_{\mathrm{w}} B_{\mathrm{w}}}=\frac{\lambda_{\mathrm{o}}}{\lambda_{\mathrm{w}}} .
$$

The well is producing at constant total liquid production $Q$, where oil production $Q_{0}$ and water production $Q_{W}$ can be obtained via formula (7). Considering the storage effect of the well, we can get the following equation:

$$
\begin{gathered}
\sum_{i} \frac{2 \pi K K_{\mathrm{ro}} h}{\mu_{\mathrm{o}} B_{\mathrm{o}} \ln \left(r_{\mathrm{e}} / r_{\mathrm{w}}\right)+S}\left(p_{i}-p_{\mathrm{wf}}\right)-\frac{C}{\Delta t}\left(P_{\mathrm{wf}}^{n+1}-P_{\mathrm{wf}}^{n}\right)=Q_{\mathrm{o}}, \\
\sum_{i} \frac{2 \pi K K_{\mathrm{rw}} h}{\mu_{\mathrm{w}} B_{\mathrm{w}} \ln \left(r_{\mathrm{e}} / r_{\mathrm{w}}\right)+S}\left(p_{i}-p_{\mathrm{wf}}\right)-\frac{C}{\Delta t}\left(P_{\mathrm{wf}}^{n+1}-P_{\mathrm{wf}}^{n}\right)=Q_{\mathrm{w}},
\end{gathered}
$$

where $C$ is the wellbore storage coefficient, $\mathrm{m}^{3} / \mathrm{MPa}$.

Equations (1), (2), (5), and (6), together with closed boundaries and initial conditions, form a well-posed equation group. Normally, Cartesian grids are commonly used in reservoir simulations. However, in reservoirs with complex geological conditions, the boundary shape of the reservoir cannot be accurately described, and each grid is not 
guaranteed to be effective. The use of PEBI (perpendicular bisection) grids here can overcome the shortcomings of Cartesian grids, which are widely used in the field of numerical simulation, especially in numerical well testing [25-27]. By fully implicitly linearizing the equations, the well-posed equations can be numerically solved [28].

\section{Production Data Interpretation Method}

According to the historical data of development and production, the bottom hole pressure can be calculated at different development times; then, the designated zone model (inner zone, outer zone, and unreconstructed zone) is used to fit and conduct the sensitivity analysis to analyze the primary and secondary fracture penetration parameters such as the permeability, fracture's half-length, the reformed area, and the bedrock's permeability. The following information indicates a vertical well whose 45-day postfractured historical production data were used for curve fitting. The following table shows the basic parameters of the reservoir.

Any change in the bottom hole pressure will be observed via tracking bedrock's permeability, fracture's half-length, and the main and secondary fracture zone permeability. The process of curve fitting and results are as follows:

(1) Establish a model, including well type (horizontal well, fracturing vertical well, and fracturing horizontal well), sedimentary facies distribution, boundary properties, and faults

(2) Enter the reservoir and layers' properties, including the top and bottom boundary types, permeability of porous media, compressibility, field depth, thickness, saturation distribution, and porosity distribution

(3) Enter the properties of the well including wellbore coordinates, fracture half-length, fracture orientation, wellbore reservoir coefficient, and skin factor

(4) Enter the flowrate and bottom hole pressure data during the curve fitting. The well produces at constant flowrate. The calculated bottom hole pressure will match the measured bottom hole pressure, which is often converted from casing pressure and dynamic liquid level

(5) Predict a set of fracturing effect evaluation parameters: the area of the core zone and the outer zone, the permeability, the reservoir permeability distribution, and the fracture half-length. During parameter adjustments, the parameters such as the area and permeability of the core area and the external area need to be adjusted repeatedly

(6) Match the calculated bottom hole pressure with the measured bottom hole pressure to obtain the fitting result. Determine whether the fitting result meets the accuracy requirement. If it does, the designated parameter is the fracturing effect evaluation parameter; if not, return to step (5).
The matrix permeability mainly affects the flow at a distant end. When the permeability of the matrix decreases, the flow capacity in a distance is weakened, which also reduces the flow capacity of the matrix to the fractures. Therefore, the permeability of the matrix affects the shape of the entire pressure curve (Figure 2(a)). The half-length of the fractures mainly affects the front part's shape of the pressure curve, and the latter half is parallel to each other; the fractures only affect the shape of the pressure curve in the early stage, because the fracture has a short half-length and the well's productivity index decreases, causing rapid drop in pressure (Figure 2(b)). The foremost section of the pressure curve almost overlaps, indicating that the inner zone permeability has a small effect on the pressure relative to the main fractures. After this section, the pressure curve begins to be nearly parallel, which means that the flow characteristics at the later stage cause no significant impact, and the main fracture permeability mainly affects the flow in well's vicinity (Figure 2(c)). The secondary fracture zone has less impact on the early pressure curve, indicating that the second outer zone mainly affects the medium-term pressure (Figure 2(d)).

\section{Application and Evaluation}

4.1. Fracturing Effect Evaluation. The method is applied to three typical vertical wells adjacent to the same block in the C Oilfield. Due to low production and lack of theoretical understanding, these three wells underwent conventional fracturing and reforming measures in the early stage, but soon, the stimulation effect disappeared, and production decreased. In recent years, the theory of "large-scale hydraulic fracturing" has been put forward and has been successful in field tests. Therefore, these three wells were subjected to volumetric hydraulic fracturing at the same time. The basic parameters of the reservoir are shown in Table 1. The fracturing parameters are shown in Table 2.

The $\mathrm{C} 1$ well was fractured and put into operation in August 2007. The initial daily production liquid was $4.12 \mathrm{~m}^{3}$, the daily oil production was $2.93 \mathrm{t}$, the water content was $14.1 \%$, and the hydrodynamic surface was $1494 \mathrm{~m}$. In April 2013, the liquid production decreased. Since then, the daily output was $0.89 \mathrm{~m}^{3}$, the daily oil production was $0.81 \mathrm{t}$, and the water content was $9.38 \%$. After the temporary plugging and fracturing in September 2013, the daily liquid production was $2.75 \mathrm{~m}^{3}$, the oil production was $1.35 \mathrm{t}$, and the output increased. The water cut is stable. The fracturing production data and the bottomhole flow pressure data are collated to obtain Figure 3.

The fracturing production data and the converted bottom hole pressure data are compared, where the production data is relatively stable and the pressure is fitted by the interval of the adjacent well interference. A total of two sections are fitted to observe the fracturing effect dynamic changes.

The first period of time is the production data for 24 days from September 19 to October 12, 2013. After curve fitting, the permeability around the fractures was $10 \mathrm{mD}$ and the permeability of the unmodified region was $0.3 \mathrm{mD}$. The fracture half-yield is $103 \mathrm{~m}$, and the average liquid 


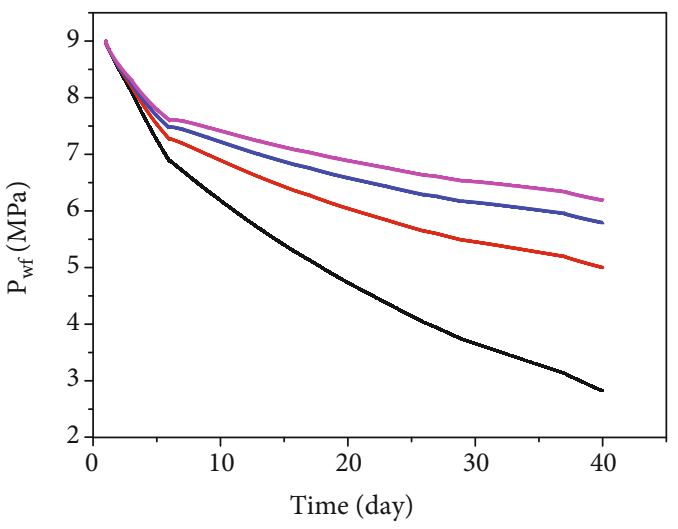

- Matrix permeability $(0.1 \mathrm{mD})$

- Matrix permeability $(0.3 \mathrm{mD})$

$\Delta$ Matrix permeability $(0.5 \mathrm{mD})$

$\nabla$ Matrix permeability $(0.7 \mathrm{mD})$

(a)

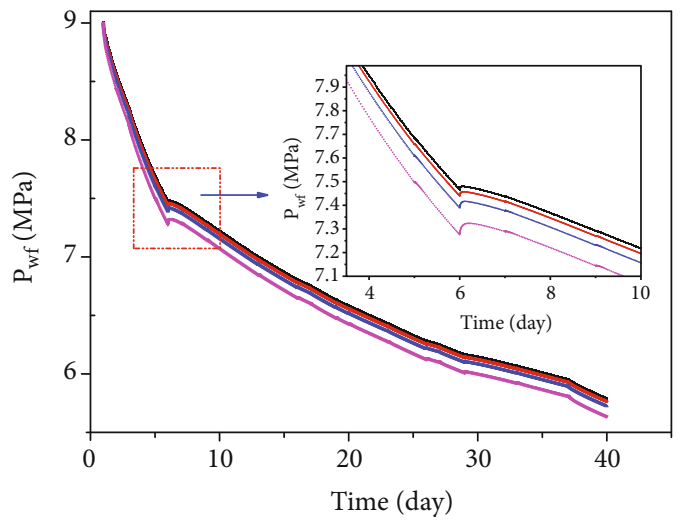

- Internal area permeability (15 mD)

- Internal area permeability $(10 \mathrm{mD})$

- Internal area permeability $(6 \mathrm{mD})$

$\nabla$ Internal area permeability $(3 \mathrm{mD})$

(c)

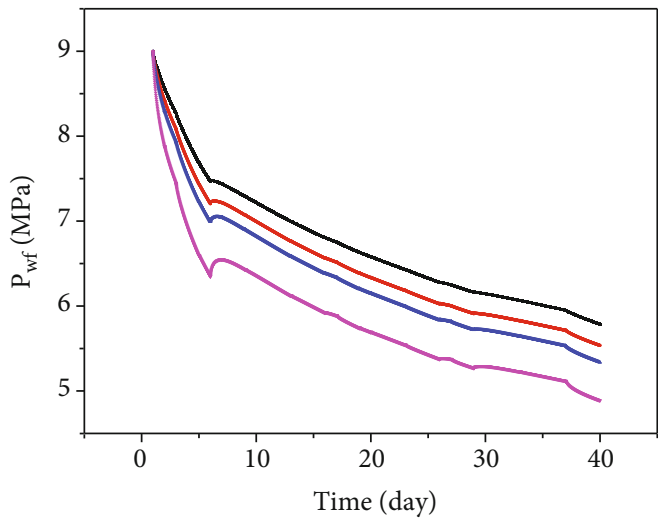

- Crack half-length (120 m)

- Crack half-length $(80 \mathrm{~m})$

- Crack half-length $(60 \mathrm{~m})$

$\nabla$ Crack half-length $(20 \mathrm{~m})$

(b)

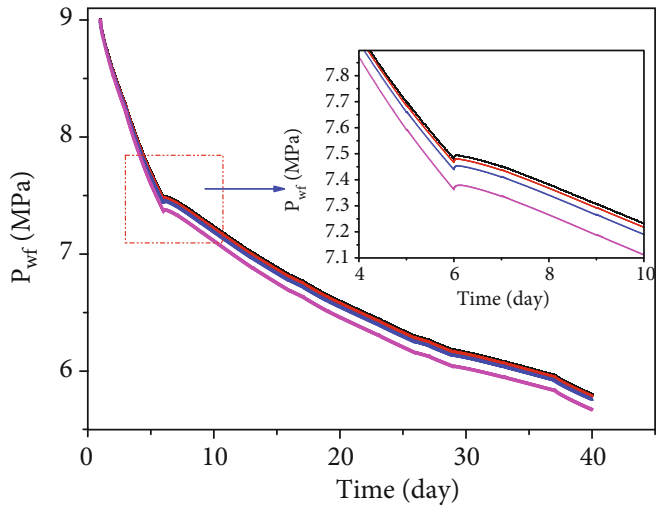

- External area permeability $(8 \mathrm{mD})$

- External area permeability $(6 \mathrm{mD})$

- External area permeability $(4 \mathrm{mD})$

$\nabla$ External area permeability $(2 \mathrm{mD})$

(d)

Figure 2: Production data fit curve.

TABle 1: Basic reservoir parameters.

\begin{tabular}{|c|c|c|c|c|}
\hline Name & & Value & Name & Value \\
\hline Reservoir thickness (m) & & 11.0 & Permeability of reservoir (mD) & 0.230 \\
\hline Porosity (\%) & & 11.80 & Rock compressibility $\left(\mathrm{MPa}^{-1}\right)$ & 0.000150 \\
\hline \multirow{2}{*}{ Formation volume factor } & Oil & 1.0500 & \multirow{2}{*}{ Initial pressure $(\mathrm{MPa})$} & \multirow[t]{2}{*}{9} \\
\hline & Water & 1.0011 & & \\
\hline \multirow{2}{*}{ Compressibility $\left(\mathrm{MPa}^{-1}\right)$} & Oil & 0.000725 & \multirow{2}{*}{ Oil viscosity $(\mathrm{mPa} \cdot \mathrm{s})$} & \multirow{2}{*}{2.24} \\
\hline & Water & 0.000413 & & \\
\hline Skin & & -0.06 & Wellbore storage coefficient $\left(\mathrm{m}^{3} * \mathrm{MPa}^{-1}\right)$ & 0.6 \\
\hline Wellbore radius $(\mathrm{m})$ & & 0.1 & & \\
\hline
\end{tabular}

production is $2.33 \mathrm{~m}^{3}$, which is $85 \%$ of the initial level. The figure below shows the permeability distribution.

It can be seen from Figure 4(a) that the SRV is not formed during the fracturing, and only a single main frac- ture is formed. Figure 4(b) is a fitted pressure history diagram.

As shown in Figure 5(a), when the flowback of fracturing fluid finished and the well was producing at early stages, the 
TABLE 2: Fracturing construction parameters.

\begin{tabular}{|c|c|c|c|c|c|c|c|}
\hline $\begin{array}{l}\text { Well } \\
\text { name }\end{array}$ & $\begin{array}{l}\text { Fracturing } \\
\text { type }\end{array}$ & $\begin{array}{c}\text { Fracture } \\
\text { pressure }(\mathrm{MPa})\end{array}$ & $\begin{array}{c}\text { Injection } \\
\text { volume }\left(\mathrm{m}^{3}\right)\end{array}$ & $\begin{array}{c}\text { Proppant } \\
\text { volume }\left(\mathrm{m}^{3}\right)\end{array}$ & $\begin{array}{c}\text { Proppant } \\
\text { concentration (\%) }\end{array}$ & $\begin{array}{c}\text { Reservoir } \\
\text { thickness (m) }\end{array}$ & $\begin{array}{l}\text { 1.5-year cumulative } \\
\text { production }(\mathrm{t})\end{array}$ \\
\hline \multirow{2}{*}{$\mathrm{C} 1$} & $\mathrm{CHF}$ & 21.5 & 117 & 41 & 35 & 8.5 & 1 \\
\hline & LHF & 31.7 & 1124 & 111.4 & 10 & 8.5 & 747.1 \\
\hline \multirow{2}{*}{ C3 } & $\mathrm{CHF}$ & 28.9 & 157 & 45 & 28.6 & 11.9 & 667.34 \\
\hline & LHF & 28.3 & 617 & 59.9 & 9.7 & 11.9 & 889.53 \\
\hline \multirow{2}{*}{ C4 } & $\mathrm{CHF}$ & 32.3 & 154 & 40 & 26 & 10 & 619.24 \\
\hline & LHF & 38.5 & 1957 & 98.3 & 5 & 10 & 891.27 \\
\hline
\end{tabular}

CHF is the abbreviation of conventional hydraulic fracturing; LHF is the abbreviation for large-scale hydraulic fracturing.

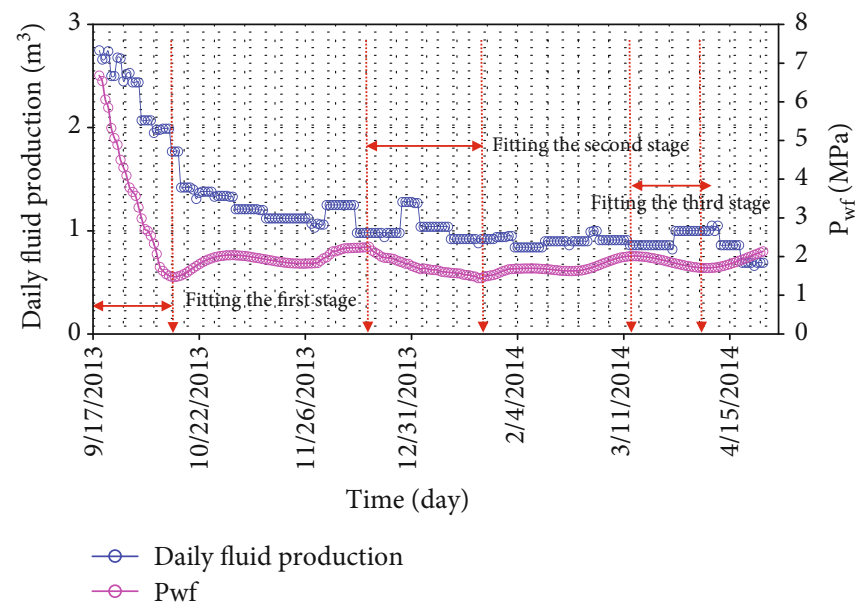

FIGURE 3: Data processing of daily production and bottom-hole flow pressure in C1 well.

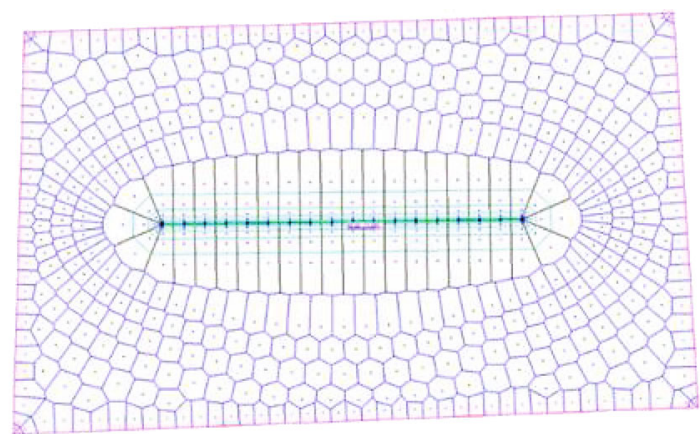

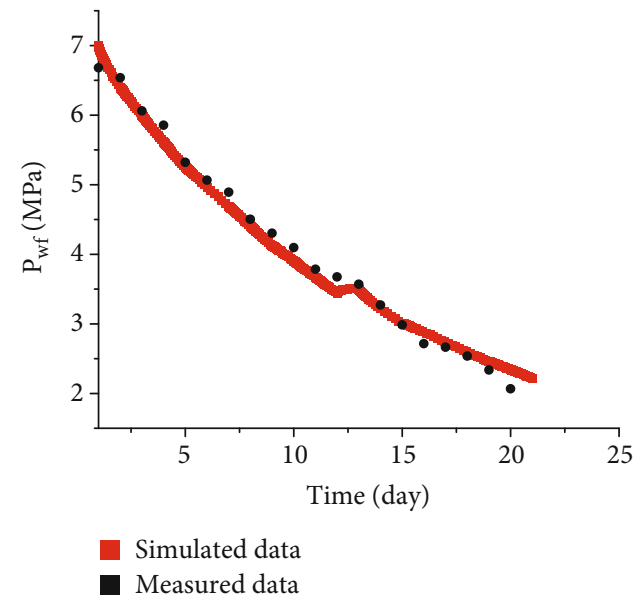

(b)

Figure 4: Pressure history of meshing and fitting of the C1 well.

pressure in the well's vicinity was as high as $7.76 \mathrm{MPa}$ due to the existence of crude oil around it. As the well kept producing, the bottom hole pressure field caused by the production gradually spread to the reservoir's boundary, making the pressure in the vicinity of well and fracture decline while the boundary pressure gradually increases. By the 5th day
(Figure 5(b)), the pressure field's effect had spread to the boundary, but the boundary pressure had not reached its maximum value, and the pressure drop around the well and the fractures remained small. As the production reaches the eighth day (Figure 5(c)), the pressure effect continued to expand toward the boundary while the influence of the 


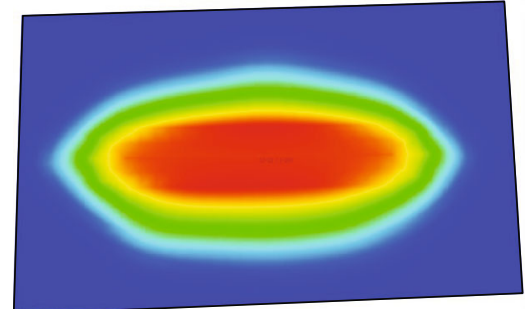

(a)

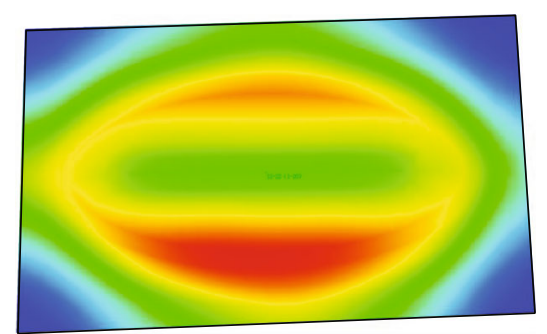

(c)

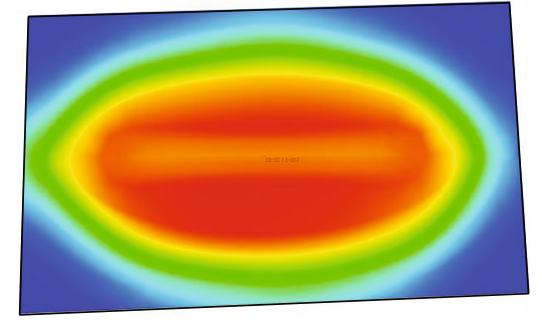

(b)

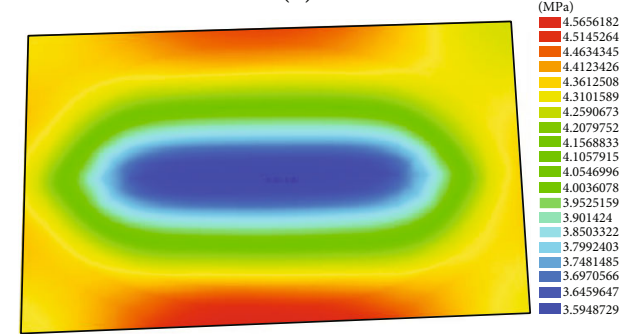

(d)

FIgURE 5: The first stage fitting pressure distribution.

TABle 3: Main parameters fitted by different fracturing types.

\begin{tabular}{|c|c|c|c|c|c|c|c|}
\hline \multirow{2}{*}{ Well name } & \multirow{2}{*}{ Fracturing type } & \multirow{2}{*}{ Fitting stage } & \multirow{2}{*}{ Crack half-length (m) } & \multicolumn{2}{|c|}{ Internal area } & \multicolumn{2}{|c|}{ External area } \\
\hline & & & & $K(\mathrm{mD})$ & $S\left(\mathrm{~m}^{2}\right)$ & $K(\mathrm{mD})$ & $S\left(\mathrm{~m}^{2}\right)$ \\
\hline \multirow{9}{*}{$\mathrm{C} 1$} & \multirow{3}{*}{$\mathrm{CHF}$} & First stage & 103 & 10 & 1 & l & I \\
\hline & & Second stage & 62 & 6 & l & I & I \\
\hline & & Third stage & 45 & 0.8 & l & I & l \\
\hline & \multirow{5}{*}{ LHF } & First stage & 110 & 15 & 6384.3 & 5 & 12073.1 \\
\hline & & Second stage & 102 & 13 & 5747.6 & 3 & 8741.8 \\
\hline & & Third stage & 82 & 8 & 5706.8 & 2.5 & 7742.5 \\
\hline & & Fourth stage & 61 & 5 & 3215.6 & 1.5 & 4318.9 \\
\hline & & Fifth stage & 53 & 2 & 5013.5 & 0.8 & 5309.6 \\
\hline & \multirow{5}{*}{$\mathrm{CHF}$} & First stage & 92 & 6.8 & 1178.5 & 3.5 & 7553.3 \\
\hline \multirow{9}{*}{ C3 } & & Second stage & 75 & 5.9 & 1049.5 & 2.5 & 3669.08 \\
\hline & & Third stage & 58 & 3.5 & 862.2 & 2 & 1950.9 \\
\hline & & Fourth stage & 53 & 3 & 756.5 & 1 & 2764.4 \\
\hline & & Fifth stage & 35 & 2 & 605 & 0.8 & 2054.7 \\
\hline & \multirow{5}{*}{ LHF } & First stage & 115 & 18 & 6875.7 & 6 & 12469.6 \\
\hline & & Second stage & 87 & 15 & 5214.8 & 4 & 10585.7 \\
\hline & & Third stage & 61 & 7 & 4185.8 & 2 & 8017.3 \\
\hline & & Fourth stage & 53 & 3.2 & 3857.3 & 1 & 7287.3 \\
\hline & & Fifth stage & 42 & 2.5 & 3567.2 & 1 & 5364.5 \\
\hline \multirow{10}{*}{$\mathrm{C} 4$} & \multirow{5}{*}{$\mathrm{CHF}$} & First stage & 90 & 7 & 1096.2 & 3 & 3125.3 \\
\hline & & Second stage & 78 & 5 & 928.6 & 2.5 & 2049.4 \\
\hline & & Third stage & 61 & 3 & 756.6 & 2 & 1561.5 \\
\hline & & Fourth stage & 43 & 2 & 543.9 & 1.5 & 1191.2 \\
\hline & & Fifth stage & 32 & 1.5 & 506.7 & 0.6 & 998.8 \\
\hline & \multirow{5}{*}{ LHF } & First stage & 118 & 20 & 7221.9 & 7 & 21219.1 \\
\hline & & Second stage & 82 & 7.6 & 6231.5 & 3 & 8256.3 \\
\hline & & Third stage & 67 & 5.5 & 5977.9 & 2.5 & 7295.3 \\
\hline & & Fourth stage & 62 & 3.8 & 5757.6 & 1.3 & 6906.8 \\
\hline & & Fifth stage & 56 & 3 & 5526.7 & 1 & 6186.9 \\
\hline
\end{tabular}




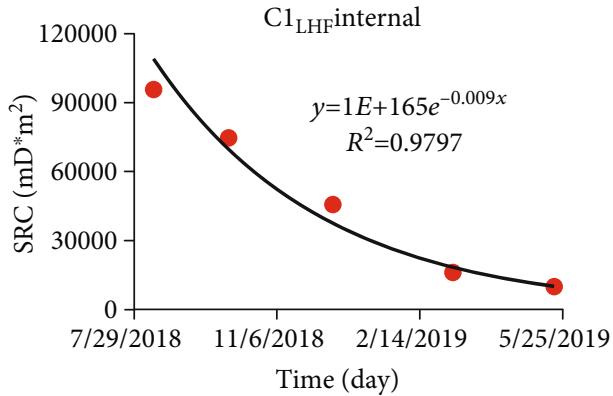

(a)

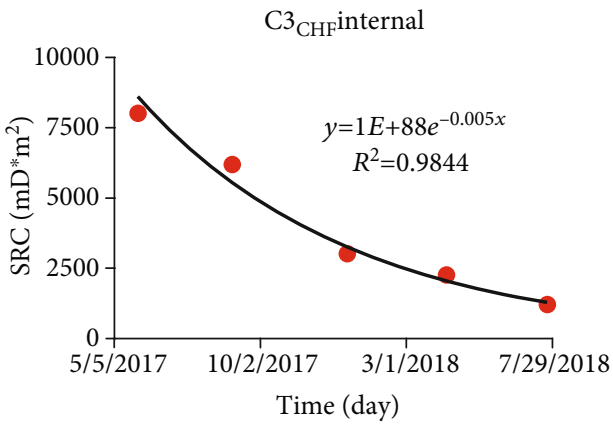

(c)

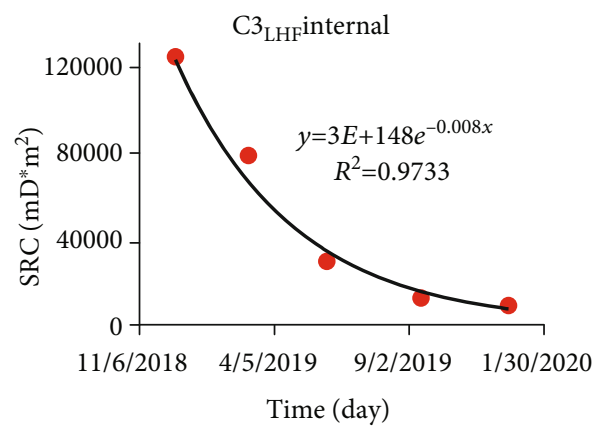

(e)

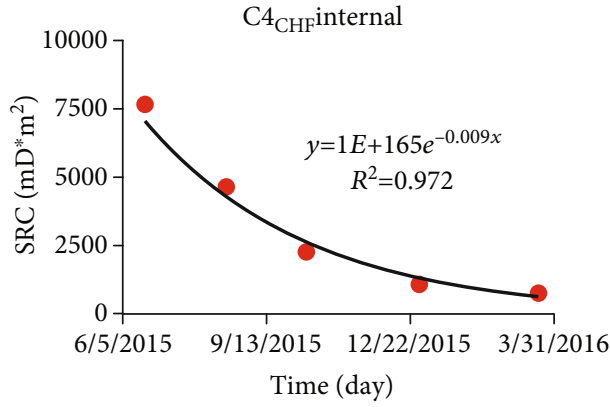

(g)

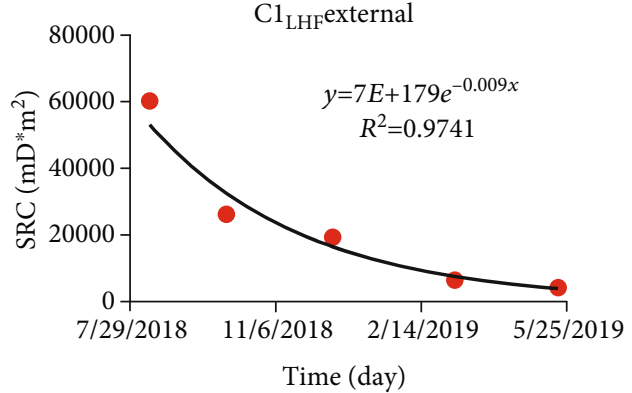

(b)

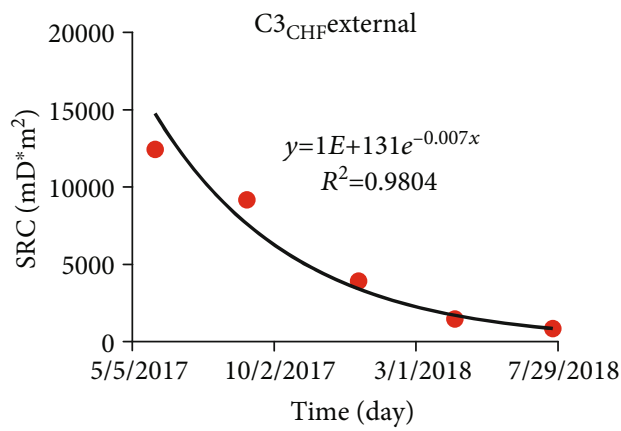

(d)

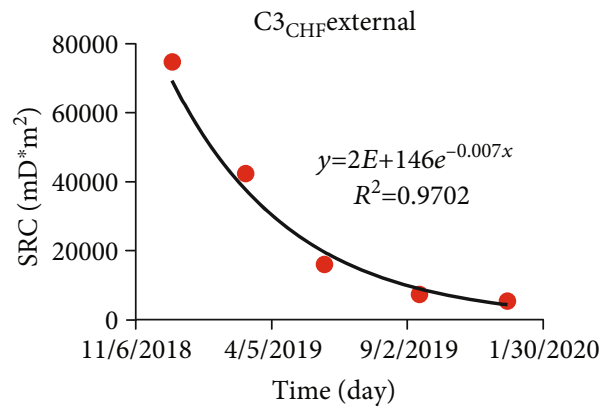

(f)

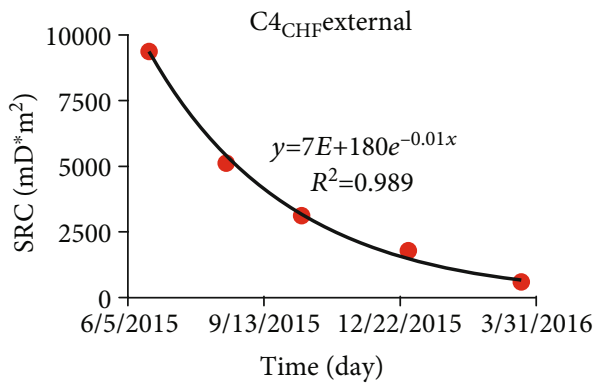

(h)

Figure 6: Continued. 


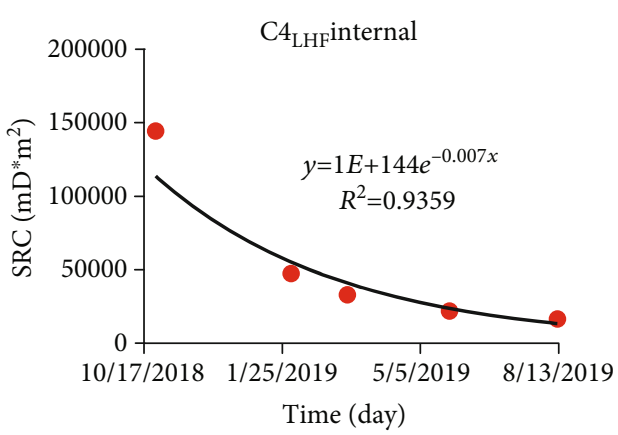

(i)

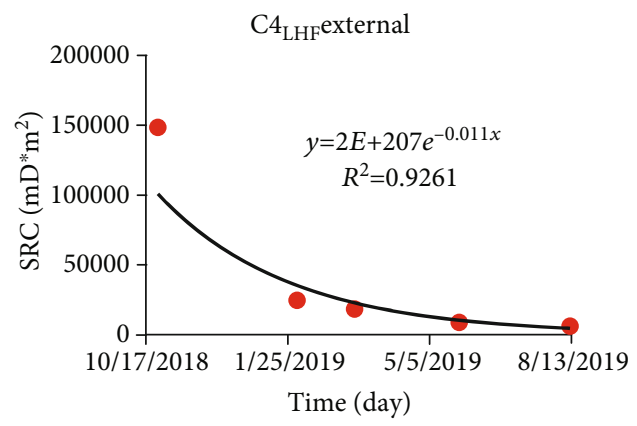

(j)

FIGURE 6: Decrease curve of SRC with time.

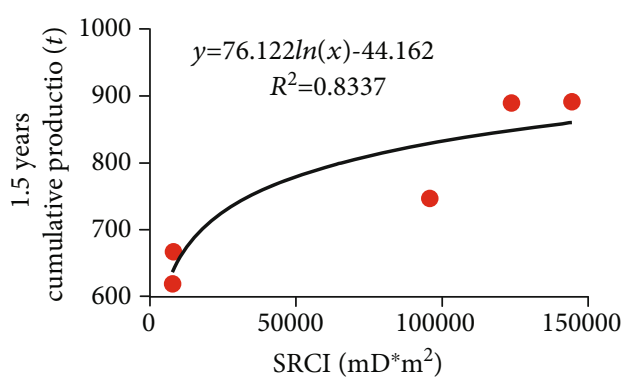

(a)

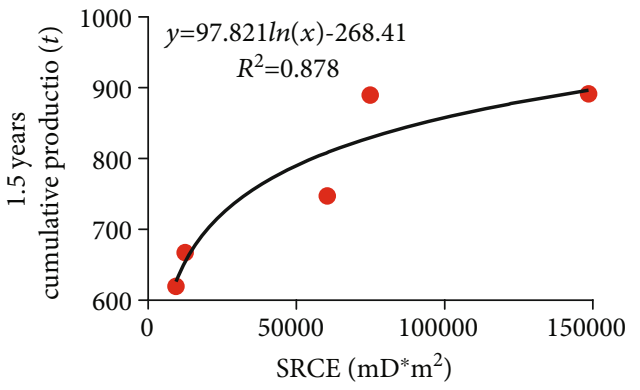

(b)

FIgURE 7: The relationship between the first stage SRC and the 1.5 cumulative production.

fracturing fluid began to disappear and formed obvious contrast to pressure drop around well and fractures. When the production went into the 19th day (as shown in Figure 5(d)), the pressure around the wellbore and the fractures was smaller than the one at the boundary, forming a depressurization cone produced by pressure drawdown.

The second period of time was 38 days of production data ranging from December 17, 2013, to January 23, 2014. By curve fitting the fracture half-length to $62 \mathrm{~m}$, the effective permeability reduced to $2 \mathrm{mD}$, and the average daily liquid production reduced to $0.96 \mathrm{~m}^{3}$, which was $35 \%$ of the initial value. The stimulation effect from fracturing reduced quickly. Hence, it is obvious that the half-length of the fractures has a great impact on the production, and as the fractures gradually close, the fracture conductivity decreases and so does and the production.

The remaining time periods of the three wells went through curve fitting according to the same method mentioned above, and the fitting results are shown in Table 3.

It can be seen from Table 3 that Mitsui's large-scale hydraulic fracturing is more effective than conventional fracturing in terms of stimulation results. Conventional fracturing in Well C1 could only form a single fracture due to the small volume of liquid and proppant. As the development progresses, fracture gradually closed the equivalent permeability and gradually reduced from $10 \mathrm{mD}$ to $6 \mathrm{mD}$; the half-length of the fracture rapidly declined with decreased production. At last, as the fracture closed, the equivalent permeability dropped to $0.8 \mathrm{mD}$. The stimulation effect caused by fracturing basically disappeared, and the produc- tion dropped to the without-fracturing level. In the stage of second large-scale hydraulic fracturing, due to the significant volume of liquid and proppant on the ground and a small ratio, a large-scale volume reconstruction area was formed underground. The fracture half-length explained was $110 \mathrm{~m}$, and the permeability of the core area was $15 \mathrm{mD}$. The area was $5747.6 \mathrm{~m}^{2}$; the permeability of the external reconstruction area was $1 \mathrm{mD}$, and the reconstruction area was $8471.8 \mathrm{~m}^{2}$. The amount of fluid entering the ground during conventional fracturing in Wells C3 and C4 has increased, forming a smaller fracture network. As the process developed, the fractures gradually closed and the stimulated effect disappeared quickly. In large-scale hydraulic fracturing process, the amount of liquid and the volume of proppant entering formation of Well C4 were much higher than those of Well C3, while the permeability and reformed area of the inner zone and the permeability of the outer zone were slightly better than those of Well C3. It can be observed that the amount of liquid and proppant entering formation, when reaching a certain level, would actually reduce the stimulation effect.

4.2. The Calculation Method and Influence Factor Analysis of the Stimulated Reservoir Conductivity (SRC). The main purpose of large-scale hydraulic fracturing is to form seepage channels with high conductivity within the stimulated reservoir, thereby reducing the resistance of oil and gas flowing from the formation to the wellbore. In terms of measuring stimulated reservoir's conductivity, it has been widely recognized that the single fracture conductivity characterization 


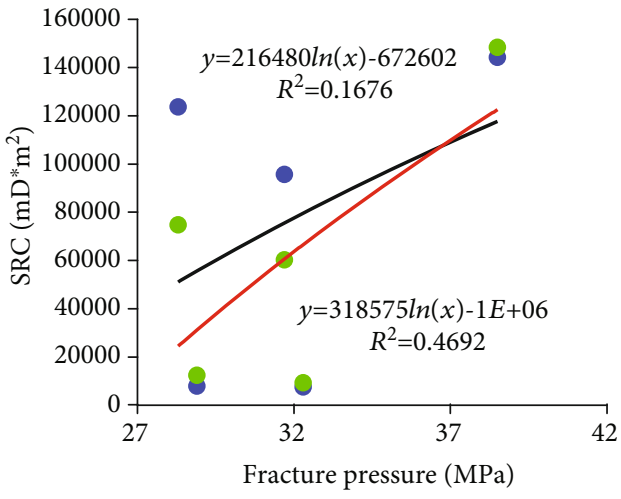

(a)

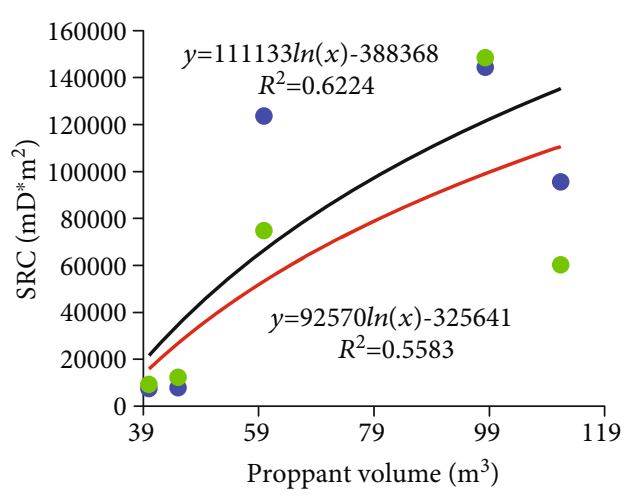

(c)

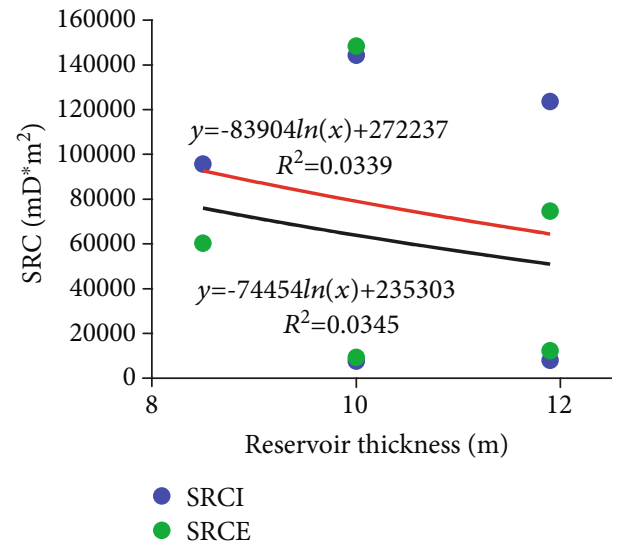

(e)

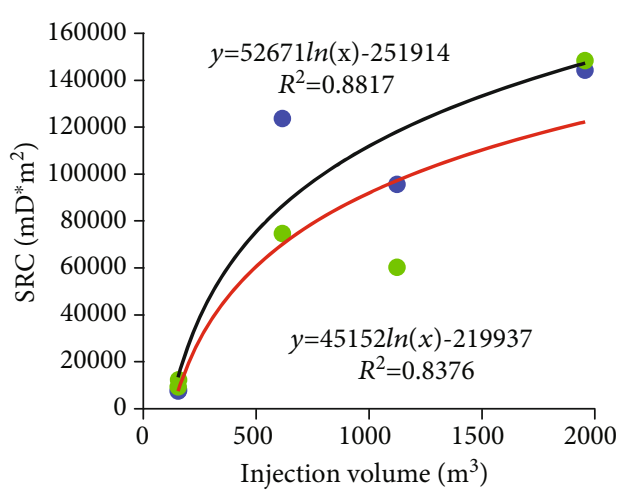

(b)

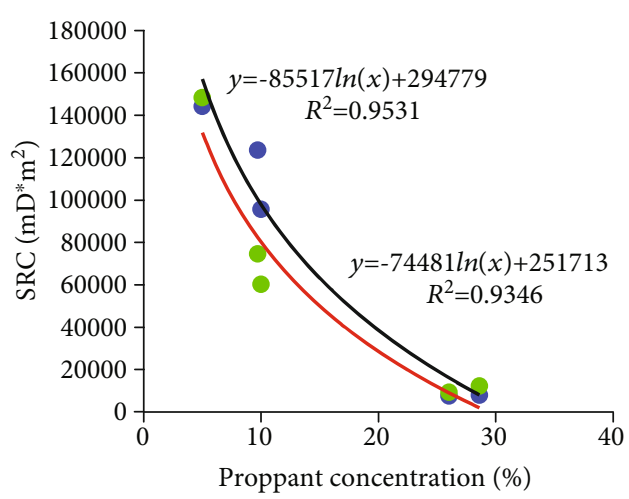

(d)

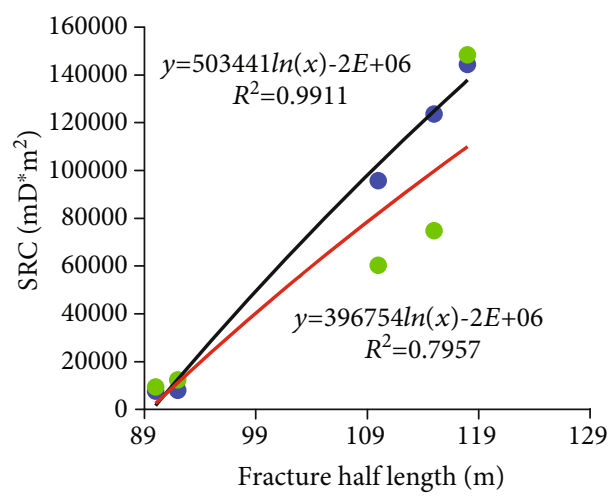

(f)

FIGURE 8: Analysis of the influence factors of the first stage SRC.

method is not suitable for fracture network conductivity. Therefore, here, the product of the equivalent permeability of the fracture network and the corresponding area was used. Its definition is expressed as follows:

$$
\mathrm{SRC}=K * A,
$$

where $A$ is the area of the stimulated reservoir, $\mathrm{m}^{2}$, and $K$ is the corresponding equivalent permeability, $\mathrm{mD}$.

It can be seen from Figure 6 that the SRC shows an exponential decrease with time, but the stimulated reservoir conductivity in the external area (SRCE) decreases faster. This characteristic is consistent with the declining law of the con- ductivity of a single fracture, which also exemplifies the SRC formula proposed in this paper. The external area was mainly composed of microfractures produced by fracturing. Along with the development process, these microfractures were more vulnerable to formation stress sensitivity and therefore could close more easily with severer conductivity decline.

Figure 7 is a diagram of the relationship between the stimulated reservoir conductivity of the internal area (SRCI) and SRCE with 1.5 years of cumulative production after fracturing. According to the diagram, the cumulative production has a strong correlation with the fracture network conductivity of the inner and outer zones, where the 
correlation coefficients are 0.83 and 0.88 , respectively. This result has proved that the fracture network conductivity defined by parameters inversely computed from this paper's numerical method is capable of reflecting the large-scale hydraulic fracturing effect and can serve in accordance with oil and gas production forecast.

In order to explore the influence caused by fracturing operating parameters on the SRC, the correlation of the first stage of SRCI and SRCE with the breakdown pressure, injection volume, proppant volume, proppant concentration, reservoir thickness, and fracture half-length was analyzed. The analysis results are shown in Figure 8.

It can be seen from Figure 8 that the first stage SRCI has no correlation with breakdown pressure and reservoir thickness but has a weak correlation with proppant volume and a strong negative correlation with proppant concentration with a correlation coefficient of 0.95 ; strong positive correlations with injection volume and fracture half-length are observed, where the correlation coefficients are 0.88 and 0.99 , respectively. The first stage SRCE has no correlation with the thickness of the oil layer but has a weak correlation with the fracture pressure, proppant volume, and fracture half-length and a strong positive correlation with the injected volume, with a correlation coefficient of 0.83 ; a strong negative correlation with sand ratio exists, and the correlation coefficient is 0.93 .

Through the above analysis, there is a good correlation between the SRC and the cumulative production, which reflects an important parameter for the effect of large-scale hydraulic fracturing. The SRC is also correlated to the injection volume, proppant volume, and proppant concentration, and therefore, it can provide guidance for the optimization of large-scale hydraulic fracturing; at the same time, it can also influence the geological characteristics of the reservoir according to the productivity of oil and gas wells and the effect of fracturing engineering. Reevaluation would improve the spatial distribution characteristics of reservoirs and the accuracy of sweet spot prediction. In the actual application process, for oil and gas wells in the same area, the relationship between the evaluation results of large-scale hydraulic fracturing engineering reconstruction effects and productivity is counted first. Then, through actual examples, the productivity of oil and gas wells after large-scale hydraulic fracturing is compared and analyzed; the stimulation effect is also affected by geological conditions such as reservoir porosity, permeability, and oil abundance. Finally, the factors that lead to productivity differences between wells are determined, such that the factors that influence the well productivity can be distinguished and reservoir's spatial distribution can be confirmed, where the evaluation of characteristics and formation body location is more accurate.

\section{Conclusion}

(1) The effect of large-scale hydraulic fracturing is better than that of conventional fracturing. The fracture network area and equivalent permeability of the internal and external regions formed by the transfor- mation are significantly better than conventional fracturing does; after large-scale hydraulic fracturing, the effect of fracturing reformation in different production stages is different, and the permeability and the area of fracturing reformation area gradually decrease with time

(2) The conductivity of the internal and external fracture network shows an exponential decrease with time, and the conductivity of the external fracture network decreases faster, which is consistent with the decrease of the conductivity of a single fracture, exemplifying and verifying the formula proposed in this paper for the fracture network's conductivity

(3) There is a good correlation between fracture network conductivity and cumulative production, which can be used to reflect the effect of large-scale hydraulic fracturing and can be used as the basis for production prediction of oil and gas wells after fracturing. At the same time, a good correlation also exists between SRC and the injection volume, proppant volume, and proppant concentration, which can provide guidance for the optimization of large-scale hydraulic fracturing design and influence the spatial distribution characteristics and sweet spot of the reservoir, providing a basis for judgment

\section{Data Availability}

The data used to support the findings of this study are available from the corresponding author upon request.

\section{Conflicts of Interest}

The authors declared that they have no conflicts of interest in this work.

\section{Acknowledgments}

We gratefully acknowledge the financial supports from the National Science and Technology Major Project (2017ZX05013-001).

\section{References}

[1] L. SUN, C. ZOU, A. JIA et al., "Development characteristics and orientation of tight oil and gas in China," Petroleum Exploration and Development, vol. 46, no. 6, pp. 1073-1087, 2019.

[2] X. Zhao, Z. Yang, W. Lin, S. Xiong, and Y. Wei, "Characteristics of microscopic pore-throat structure of tight oil reservoirs in Sichuan Basin measured by rate-controlledmercury injection," Open Physics, vol. 16, no. 8, pp. 675-684, 2018.

[3] X. L. Zhao, Z. M. Yang, W. Lin et al., "Fractal study on pore structure of tight sandstone based on full-scale map," International Journal of Oil, Gas and Coal Technology, vol. 22, no. 2, pp. 123-138, 2019.

[4] Z. Wang, Z. Yang, Y. Ding et al., "A multi-linear fractal model for pressure transient analysis of multiple fractured horizontal 
wells in tight oil reservoirs including imbibition," Fractals, vol. 27, no. 1, p. 1940004, 2019.

[5] W. Shen, F. Song, X. Hu, G. Zhu, and W. Zhu, "Experimental study on flow characteristics of gas transport in micro- and nanoscale pores," Scientific Reports, vol. 9, no. 1, 2019.

[6] X. Wang, X. Peng, S. Zhang, Z. du, and F. Zeng, "Characteristics of oil distributions in forced and spontaneous imbibition of tight oil reservoir," Fuel, vol. 224, no. 23, pp. 280-288, 2018.

[7] W. Qi, X. Yun, Z. Shouliang, W. Tengfei, G. Baoshan, and W. Guotao, "The core theories and key optimization designs of volume stimulation technology for unconventional reservoirs," Acta Petrolei Sinica, vol. 35, no. 4, pp. 706-714, 2014.

[8] Q. Wu, Y. Xu, X. Wang, T. Wang, and S. Zhang, "Volume fracturing technology of unconventional reservoirs: connotation, design optimization and implementation," Petroleum Exploration and Development, vol. 39, no. 3, pp. 377-384, 2012.

[9] Y. Wang, X. Ma, Y. Zhang, and J. He, "Optimization of volumetric fracturing parameters in the formation of Chang 8," Science Technology and Engineering, vol. 14, no. 29, pp. 189193, 2014.

[10] X. Guo, J. Li, G. Liu et al., "Numerical simulation of casing deformation during volume fracturing of horizontal shale gas wells," Journal of Petroleum Science and Engineering, vol. 172, no. 2, pp. 731-742, 2019.

[11] L. Yu, J. Wang, C. Wang, and D. Chen, "Enhanced tight oil recovery by volume fracturing in Chang 7 reservoir: experimental study and field practice," Energies, vol. 12, no. 12, p. 2419, 2019.

[12] C. Cipolla and C. Wright, "Diagnostic techniques to understand hydraulic fracturing: what? why? and how?" in SPE/CERI Gas Technology Symposium, Calgary, Alberta, Canada, 2000.

[13] R. Perrine, "Analysis of pressure-buildup curves," in Drilling and Production Practice, American Petroleum Institute, 1956.

[14] J. Martin, "Simplified equations of flow in gas drive reservoirs and the theoretical foundation of multiphase pressure buildup analyses," Transactions of the AIME, vol. 216, no. 1, pp. 321323, 1959.

[15] K. Serra, A. Peres, and A. Reynolds, "Well-test analysis for solution-gas-drive reservoirs: part 2-buildup analysis," SPE Formation Evaluation, vol. 5, no. 2, pp. 133-140, 1990.

[16] Q. Y. Li, P. C. Li, W. Pang, D. Li, H. Liang, and D. Lu, "A new method for production data analysis in shale gas reservoirs," Journal of Natural Gas Science and Engineering, vol. 56, no. 3, pp. 368-383, 2018.

[17] D. Hatzignatiou, A. Peres, and A. Reynolds, "Effect of wellbore storage on the analysis of multiphase flow pressure data," SPE Formation Evaluation, vol. 9, no. 3, pp. 219-227, 1994.

[18] Y. Zhang and D. Yang, "Evaluation of transient pressure responses of a hydraulically fractured horizontal well in a tight reservoir with an arbitrary shape by considering stresssensitive effect," Journal of Petroleum Science and Engineering, vol. 202, 2021.

[19] W. Xu, J. H. Le Calvez, and M. J. Thiercelin, "Characterization of hydraulically-induced fracture network using treatment and microseismic data in a tight-gas sand formation: a geomechanical approach," in SPE Tight Gas Completions Conference, San Antonio, Texas, USA, 2009.

[20] T. Lei, "Well test analysis of oil-water two-phase flow considering wellbore reservoir," Well Testing, vol. 9, no. 3, pp. 15$17,2000$.
[21] P. Puchyr, "A numerical well test model," in Society of Petroleum Engineers, Low Permeability Reservoirs Symposium, Denver, Colorado, 1991.

[22] R. Archer and R. Horne, "The Green element method for numerical well test analysis," in SPE Annual Technical Conference and Exhibition, Dallas, Texas, 2000.

[23] B. R. Meyer and L. W. Bazan, "A discrete fracture network model for hydraulically induced fractures - theory, parametric and case studies," in SPE Hydraulic Fracturing Technology Conference, The Woodlands, Texas, USA, 2011.

[24] C. Y. Xu, P. C. Li, Z. W. Lu, J. Liu, and D. Lu, "Discrete fracture modeling of shale gas flow considering rock deformation," Journal of Natural Gas Science and Engineering, vol. 52, no. 5, pp. 507-514, 2018.

[25] C. Palagi and K. Aziz, "Use of Voronoi grid in reservoir simulation," SPE Advanced Technology Series, vol. 2, no. 2, pp. 6977, 1994.

[26] C. Pinzon, H. Chen, and L. Teufel, "Numerical well test analysis of stress-sensitive reservoirs," in SPE Rocky Mountain Petroleum Technology Conference, Keystone, Colorado, 2001.

[27] M. Nnadi and M. Onyekonwu, "Numerical welltest analysis," in Nigeria Annual International Conference and Exhibition, Abuja, Nigeria, 2004.

[28] D. L. Li, W. S. Zha, S. Liu, L. Wang, and D. Lu, "Pressure transient analysis of low permeability reservoir with pseudo threshold pressure gradient," Journal of Petroleum Science and Engineering, vol. 147, no. 2, pp. 308-316, 2016. 